\title{
Thermal Response of Compartment Boundaries to Fire
}

\author{
J. R. MEHAFFEY and T. Z. HARMATHY \\ Division of Building Research \\ National Research Council of Canada \\ Ottawa, Canada
}

\section{ABSTRACT}

A series of full-scale room burn experiments has been conducted on fully-developed fires to study their destructive potentials in terms of the thermal response of room boundaries. It is shown that normalized heat load is a convenient measure of the destructive potential (severity) of fire, irrespective of the nature of the boundary elements. A mathematical model for calculating normalized heat load yields satisfactory predictions, given the amount of combustible material in the compartment, its geometry, the thermal properties of the boundaries, and the size of ventilation openings.

\section{INTRODUCTION}

The conditions prevailing in a room during the fully-developed stage of a fire have been studied extensively over the last 25 years (1). Theoretical analyses $(2,3)$ have shown that the normalized heat load is a measure of the destructive potential of fire (fire severity) and is capable of providing the link between the severity of real world fires and that of fire resistance tests. Although numerous room-burn experiments have been reported in the literature, however, there is a paucity of information that can be used to determine normalized heat load. To test the predictive capabilities of a model developed by the authors, it became necessary to conduct a series of full-scale room burn experiments. The normalized heat 1oad values derived from such a test series show good agreement with model predictions and thereby prove the validity of the normalized heat load concept, irrespective of the thermal. characteristics of the enclosure boundaries.

NORMALIZED HEAT LOAD

Normalized heat load is defined as

$$
H=\frac{E}{\sqrt{k \rho c}}
$$

where $E$ is the heat absorbed per unit surface area of the enclosure during the fire, and $\sqrt{k \rho c}$ is the thermal absorptivity of the boundaries ( $k$ is thermal conductivity, $p$ is density, and $c$ is specific heat). It has been shown (2) that the normalized heat load does not depend on the temperature history of the fire, and that it can be calculated from the maximum temperature rise within the enclosure boundary. 
Usually the various boundaries of an enclosure are built of different materials. In such cases the thermal absorptivity of the enclosure is interpreted as the surface-weighted average of the thermal absorptivity for the individual boundaries.

$$
\begin{aligned}
\sqrt{\mathrm{KPC}} & =\frac{1}{\mathrm{~A}} \sum_{i} A_{i} \sqrt{\mathrm{k}_{i} \mathrm{p}_{i} \mathrm{c}_{i}} \\
A & =\sum_{i} A_{i}
\end{aligned}
$$

Subscript $i$ in this expression relates to information pertinent to the 1 -th boundary. The letter A stands for total boundary surface area. Numerical studies show that in a compartment lined with materials of differing thermal absorptivity the normalized heat loads imposed on varlous boundary elements are approximately identical (4). Loosely referred to as the "theorem of uniformity of normalized heat loads," this implies that the destructive potential of fire for all the boundaries is identical.

\section{COMPARTMENT FIRE MODELS}

A mathematical model of fully-developed compartment fires involving cellulosic fuels has been formulated (5). (Statistics indicate that combustible materials in buildings sti11 consist predominant $1 \mathrm{y}$ of cellulosics.) According to the model, the nature of such fires depends primarily on five variables:

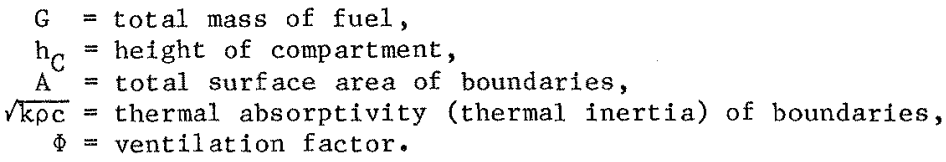

The ventilation factor characterizes the rate of entry of air into a burning compartment. Under experimental conditions the rate of entry of air is not augmented by wind or drafts, and the ventilation factor can be expressed with the aid of the dimensions of the ventilation opening.

$$
\Phi=\rho_{a} A_{V} \sqrt{g_{V}}
$$

where $\rho_{a}$ is the density of atmospheric air, $A_{V}$ is the area of ventilation. opening, $h_{V}$ is the height of that opening, and $g$ is the gravitational constant. It has been shown (6) that with cellulosic fuel a fire is ventilation-controlled if

$$
<0.263 \varphi G
$$

Otherwise, it is fuel-surface-controlled. $\varphi$ is the specific surface of the fuel (for typically furnished rooms, $\varphi \simeq 0.13 \mathrm{~m}^{-2} / \mathrm{kg}$ ).

In its most general form the compartment fire model requires the numerical solution (by iteration) of six coupled equations to determine the values of six process variables and the normalized heat load (5). If the normalized heat load is the only information required, however, one can bypass the iterative technique and employ the approximate formula (7)

$$
\mathrm{H}=10^{6} \frac{(11.0 \delta+1.6) \mathrm{G}}{\mathrm{A} \sqrt{\mathrm{k \rho c}}+935 \sqrt{\Phi G}}
$$


In this equation $\delta$ is, in a loose sense, the fraction of the fuel energy released inside the compartment. (This interpretation of $\delta$ is strictly appropriate only for ventilation-controlled fires. At very high air flow rates $\delta$ becomes a correction factor.) It is primarily a function of the height of the compartment $\left(h_{C}\right)$ and the ventilation factor $(\Phi)$ and is given by the expression

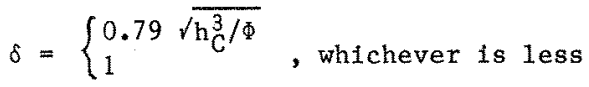

\section{ROOM BURNS}

Seventeen full-scale room burn experiments were conducted to test the theory and answer two questions:

1) Does the model of fully-developed compartment fires, in both iterative and analytic forms, predict accurately the normalized heat load?

2) Does the theorem of uniformity of normalized heat load hold?

A preliminary account of the first ten of these burns has been published (8). They were conducted in a concrete block room with one wall fitted with either a door or a window; wall, celling, and floor panels were attached directly to the concrete blocks. For this series of room burns the inner floor dimensions were in the range $(2.39$ to $2.47 \mathrm{~m}) \times(3.59$ to $3.66 \mathrm{~m})$ and the inner height was in the range 2.54 to $2.56 \mathrm{~m}$. The total surface area, $\mathrm{A}$, of the celling, floor, and walls (excluding the opening) for each of the room burns is listed in Table $I$.

Eight wooden cribs supported $100 \mathrm{~mm}$ above the floor on bricks were distributed over the floor in each burn experiment. The cribs were constructed of pine sticks measuring $4 \times 4 \times 84 \mathrm{~cm}$. To drive the fire to the fully-developed stage as quickly as possible the cribs were ignited simultaneously. The quantity of fuel per unit floor area was chosen to be representative of that found in practice. The total mass of wood for each burn, G, is 1isted in Table I. Fires involving approximately $130 \mathrm{~kg}$ of wood represented a fuel load per unit floor area of about $15 \mathrm{~kg} \mathrm{~m}^{-2}$, typical of a hotel room; those involving approximately $240 \mathrm{~kg}$ of wood had a fuel 1 oad per unit floor area of about $27 \mathrm{~kg} \mathrm{~m}^{-2}$, typical of an office room (9).

Five materials were chosen to line the room: brick, insulating fire brick, a fibrefrax board, gypsum wallboard and normal-weight concrete; thermal properties and thicknesses of linings are listed in Table II. As a set, they span the range of thermal properties likely to be encountered in buildings. The first three (brick, insulating fire brick, and fibrefrax board) were used most extensively since their properties remain relatively unchanged from test to test and walls did not have to be replaced after every experiment.

In each test at least two of the five materials were present as Iining. In tests $A-D$ the floor and ceiling were lined with fibrefrax and the walls with brick. In tests E-J, the floor and celling were lined with fibrefrax, the two long walls with brick, and the end walls with insulating firebrick. In tests $\mathrm{K}-\mathrm{M}$, the floor and ceiling were lined with fibrefrax and the walls with insulating firebrick. The last four tests, $N-Q$, were conducted by a colleague, $K$. Chot, as part of an independent research project (10). In these the ceiling was lined with fibrefrax, the floor with normal-weight concrete, 
TABLE I

Summary - Room Burns

\begin{tabular}{|c|c|c|c|c|c|c|c|c|}
\hline Test & $\begin{array}{r}A \\
m^{2}\end{array}$ & $\begin{array}{r}\mathrm{G} \\
\mathrm{kg}\end{array}$ & $\frac{\Phi}{\mathrm{kg} s^{-1}}$ & $\begin{array}{c}\sqrt{\mathrm{k} \rho c} \\
\mathrm{~J}^{-2} \mathrm{~s}^{-\frac{1}{2}} \mathrm{~K}^{-1}\end{array}$ & $\begin{array}{l}\psi^{+} \\
\mathrm{m}^{2} / \mathrm{kg}\end{array}$ & ${ }_{\mathrm{C}}^{\mathrm{h}}$ & $\beta^{+4}$ & $\begin{array}{l}\text { Burning * } \\
\text { mode }\end{array}$ \\
\hline A & 48.60 & 133.4 & 3.56 & 868 & 0.21 & 2.56 & 1.0 & VC \\
\hline $\mathrm{B}$ & 48.60 & 236.6 & 3.56 & 868 & 0.21 & 2.56 & 1.0 & VC \\
\hline C & 48.31 & 242.3 & 5.49 & 866 & 0.21 & 2.56 & 1.0 & VC \\
\hline $\mathrm{D}$ & 48.31 & 133.1 & 5.49 & 866 & 0.21 & 2.56 & 1.0 & VC \\
\hline $\mathrm{E}$ & 48.53 & 130.7 & 3.43 & 666 & 0.21 & 2.56 & 1.0 & VC \\
\hline $\mathrm{F}$ & 48.26 & 135.7 & 5.25 & 667 & 0.21 & 2.56 & 1.0 & VC \\
\hline G & 47.91 & 130.8 & 7.93 & 668 & 0.21 & 2.56 & 1.0 & ES \\
\hline $\mathrm{H}$ & 48.53 & 240.3 & 3.43 & 666 & 0.21 & 2.56 & 1.0 & VC \\
\hline$I$ & 48.26 & 240.0 & 5.25 & 667 & 0.21 & 2.56 & 1.0 & VC \\
\hline$J$ & 47.91 & 240.0 & 7.93 & 668 & 0.21 & 2.56 & 1.0 & VC \\
\hline $\mathrm{K}$ & 48.41 & 133.2 & 3.43 & 344 & 0.21 & 2.56 & 1.0 & $\mathrm{VC}$ \\
\hline L & 48.14 & 242.1 & 5.25 & 344 & 0.21 & 2.56 & 1.0 & VC \\
\hline M & 48.14 & 137.6 & 5.25 & 344 & 0.21 & 2.56 & 1.0 & VC \\
\hline $\mathrm{N}$ & 46.74 & 240.0 & 3.31 & 725 & 0.21 & 2.54 & 1.0 & VC \\
\hline 0 & 46.74 & 240.0 & 3.31 & 725 & 0.21 & 2.54 & 1.0 & VC \\
\hline $\mathrm{P}$ & 46.74 & 240.0 & 3.31 & 725 & 0.21 & 2.54 & 1.0 & Vo \\
\hline$Q$ & 46.74 & 240.0 & 3.31 & 725 & 0.21 & 2.54 & 1.0 & VC \\
\hline
\end{tabular}

+ Exposed surface area of fuel is $4 \mathrm{G}$

* $\mathrm{VC}=$ Ventilation-controlled; $\mathrm{FS}=$ Fuel-surface controlled

and the walls with gypsum wallboard. Two of the walls had narrow strips $(0.30 \mathrm{~m}$ wide $\times 2.54 \mathrm{~m}$ high) of insulating firebrick to facilitate comparison with tests E-M. The overall thermal absorptivity of the compartment for each burn is listed in Table $\mathrm{I}$. This quantity was calculated employing Eq. (2), assuming that half the floor area was lined with wood. To calculate the normalized heat load, thermocouples were installed within the lining materials at depths indicated in Tab1e II. Typ1cal1y, nine thermocouples were embedded in each of the walls, in the ceiling and the floor.

The area of the ventilation opening was chosen to be approximately $9 \%$, $12 \%$, or $16 \%$ of the compartment floor area. In tests $G$ and $J$ this opening was a doorway $0.69 \times 2.10 \mathrm{~m}$. In all other cases the opening was a window whose approximate dimensions were either $0.7 \times 1.2 \mathrm{~m}$ or $0.7 \times 1.6 \mathrm{~m}$. The ventilation factors, calculated from Eq. (4), are listed in Table I.

The quantity of fuel, the overall thermal absorptivity of the boundaries, and the size of the ventilation opening (and to a lesser degree the area of the boundaries) were varied from test to test, as shown in Table $I$. The normalized heat loads imposed on the boundaries by each fire have been calculated by both the iterative form of the model and its analytic form (Eq. (6)); the results are tabulated in Table III. The specific fuel area of the cribs employed in these burns was fairly large: $\varphi \simeq 0.21 \mathrm{~m}^{2} / \mathrm{kg}$. Consequent $1 y$, only one fire, test $G$, was fuel-surface-controlled (cf. Eq. (5)); all others were ventilation-controlled. 
Properties of Lining Materials

(Thermal properties averaged over temperature range $300-900 \mathrm{~K}$ )

\begin{tabular}{|c|c|c|c|c|c|c|c|}
\hline Material & $\begin{array}{c}k \\
\left(W n^{-1} k^{-1}\right)\end{array}$ & $\begin{array}{c}\rho \\
\left(\mathrm{kg} \mathrm{m} \mathrm{m}^{-3}\right)\end{array}$ & 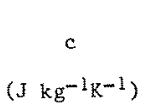 & $\begin{array}{c}\sqrt{\mathrm{k} \rho \mathrm{c}} \\
\left(J \mathrm{~m}^{-2} \mathrm{~s}^{-\frac{1}{2} \mathrm{~K}^{-1}}\right)\end{array}$ & $\begin{array}{l}k / \rho c \\
\left(\mathrm{~m}^{2} \mathrm{~s}^{-1}\right)\end{array}$ & $\begin{array}{l}\text { Thickness } \\
\text { of lining } \\
\text { materlal } \\
\text { (m) }\end{array}$ & $\begin{array}{l}\text { Thermocouple } \\
\text { depth in } \\
\text { lining } \\
x(m)\end{array}$ \\
\hline $\begin{array}{l}\text { Normal-wt } \\
\text { concrete }\end{array}$ & 1.68 & 2200 & 1300 & 2192 & $5.87 \times 10^{-7}$ & 0.100 & - \\
\hline Brick & 0.80 & 1935 & 1025 & 1260 & $4.03 \times 10^{-7}$ & 0.057 & 0.027 \\
\hline $\begin{array}{l}\text { Gypsum } \\
\text { wallboard }\end{array}$ & 0.27 & 680 & 3000 & 742 & $1.32 \times 10^{-7}$ & 0.0159 & 0.0159 \\
\hline $\begin{array}{l}\text { Insulating } \\
\text { firebrick }\end{array}$ & 0.25 & 722 & 1000 & 425 & $3.46 \times 10^{-7}$ & 0.063 & 0.022 \\
\hline $\begin{array}{l}\text { Fibrefrax } \\
\text { board }\end{array}$ & 0.072 & 318 & 750 & 131 & $3.02 \times 10^{-7}$ & 0.038 & 0.0127 \\
\hline Wood & 0.15 & 550 & 2300 & 436 & $1.19 \times 10^{-7}$ & - & - \\
\hline
\end{tabular}

EXPERIMENTAL DETERMINATION OF NORMALIZED HEAT LOAD

The experimental values of the normalized heat load were determined from temperature measurements, using thermocouples installed in the lining materials. (As indicated earlier, the normalized heat load is related directly to the maximum temperature rise at critical depths within the boundary elements (2).) Both experimental results and model predictions are tabulated in Table III. It is clear that the iterative and analytic forms of the fire model provide satisfactory accuracy.

A comparison of the normalized heat load imposed on brick, insulating firebrick, and fibrefrax with the predictions of the iterative form of the fire model are provided in Figures 1, 2, and 3, respectively. Model predictions and experimental findings agree to within $\pm 10 \%$ for both brick and insulating fire brick, despite the large differences in their thermal properties. Agreement for fibrefrax board is to within $\pm 20 \%$ only.

To investigate the validity of the theorem of uniformity for normalized heat loads, those imposed on the different lining materials during the burns are compared in Figure 4. Fibrefrax is compared with insulating firebrick, fibrefrax with brick, and insulating firebrick with brick. The results for the material with the lower thermal absorptivity (in each pair) are plotted along the $y$-axis. Agreement between theory and experiment is apparently good.

\section{CONCLUSION}

Experiments in which a series of full-scale room burns were carried out to study the thermal assault a fully-developed fire mounts against room boundaries have demonstrated the capability of a compartment fire model to assess the severity of fires in terms of the normalized heat 1oad. The model predictions agree with experimental findings to within $\pm 10 \%$. It is believed that this is the first time the predictive capability of a model has been 
NORMALIZED HEAT LOAD

(UNITS $10^{4} 5^{1 / 2} \mathrm{~K}$ )

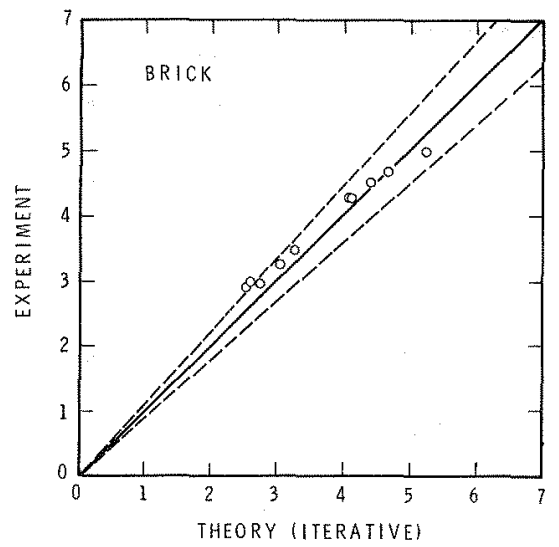

Figure 1. Comparison of normalized heat loads, as derived from experiments and from the model. Lining material: brick. (Points falling between dashed lines represent agreement of better than $\pm 10 \%$ between experiment and theory)

NOR期ALZZLD HEAT LOAD

(UNITS $10^{4} \mathrm{~s}^{1 / 2} \mathrm{~K}$ )

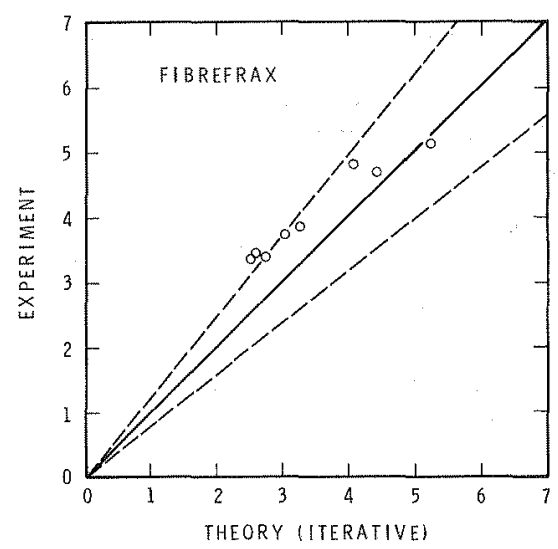

Figure 3. Comparis on of normalized heat loads, as derived from experiments and from the model. Lining material: fibrefrax board. (Points falling between the dashed 1 ines represent agreement of better than $\pm 20 \%$ between experiment and theory)
NORMALIZED HEAT LOAD

(UNITS $10^{4} \mathrm{~s}^{1 / 2} \mathrm{~K}$ )

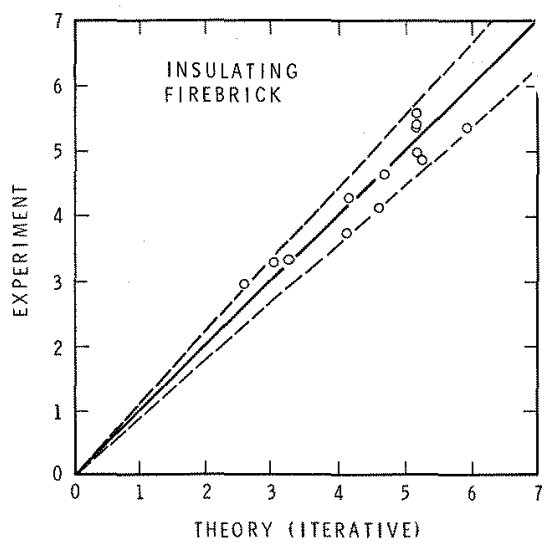

Figure 2. Comparison of normalized heat loads, as derived from measurements and from the model. Lining material: insulating firebrick. (Points falling between dashed lines represent agreement of better than $\pm 10 \%$ between experiment and theory)

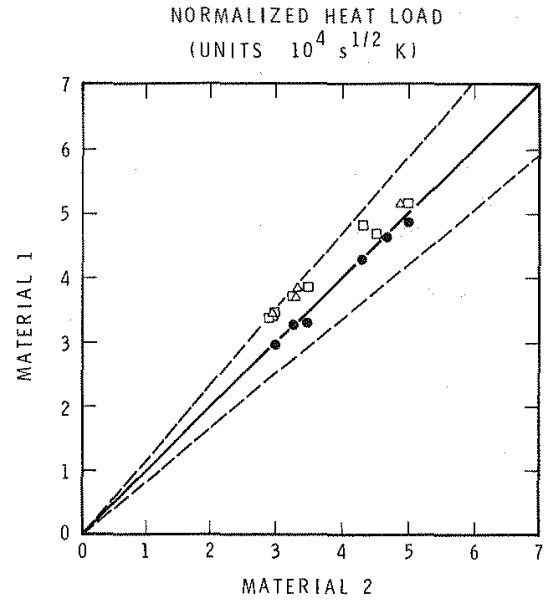

Figure 4. Comparison of measured normalized heat loads imposed on different lining materials. Fibrefrax compared with insulating firebrick ( $\Delta)$, fibrefrax with brick (0), insulating firebrick with brick (o) 
TABLE TII

Normalized Heat load $\left(10^{4} \mathrm{~s}^{\frac{1}{2}} \mathrm{~K}\right)$

\begin{tabular}{|c|c|c|c|c|c|}
\hline \multirow[b]{2}{*}{ Test } & \multicolumn{2}{|c|}{ Theory } & \multicolumn{3}{|c|}{ Experiment } \\
\hline & Analytlo & Iterative & Brick & Firebrick & Wibrefrax \\
\hline A & 2.69 & 2.76 & 2.97 & - & 3.41 \\
\hline$B$ & 4.30 & 4.44 & 4.52 & - & 4.71 \\
\hline$c$ & 4.02 & 4.09 & 4.31 & - & 4.83 \\
\hline $\mathrm{D}$ & 2.50 & 2.53 & 2.91 & - & 3.39 \\
\hline $\mathrm{E}$ & 3.16 & 3.27 & 3.48 & 3.34 & 3.87 \\
\hline $\mathrm{F}$ & 2.99 & 3.05 & 3.27 & 3.30 & 3.75 \\
\hline$G$ & 2.65 & 2.61 & 3.00 & 2.97 & 3.47 \\
\hline $\mathrm{H}$ & 5.12 & 5.26 & 4.99 & 4.88 & 5.17 \\
\hline I & 4.63 & 4.69 & 4.68 & 4.66 & - \\
\hline $\mathrm{J}$ & 4.15 & 4.15 & 4.29 & 4.30 & - \\
\hline $\mathrm{K}$ & 4.58 & 4.60 & - & 4.14 & - \\
\hline $\mathrm{L}$ & 6.11 & 5.92 & - & 5.38 & - \\
\hline M & 4.16 & 4.12 & - & 3.77 & - \\
\hline $\mathrm{N}$ & 5.02 & 5.17 & - & 5.13 & - \\
\hline 0 & 5.02 & 5.17 & - & 5.17 & - \\
\hline $\mathrm{P}$ & 5.02 & 5.17 & - & 5.34 & - \\
\hline$Q$ & 5.02 & 4.17 & - & 4.01 & - \\
\hline
\end{tabular}

demonstrated. Further experiments are planned to study fue1-surfacecontrolled fires, the effect of compartment helght, and the influence of non-charring fuels on the normalized heat load.

\section{NOMENCLATURE}

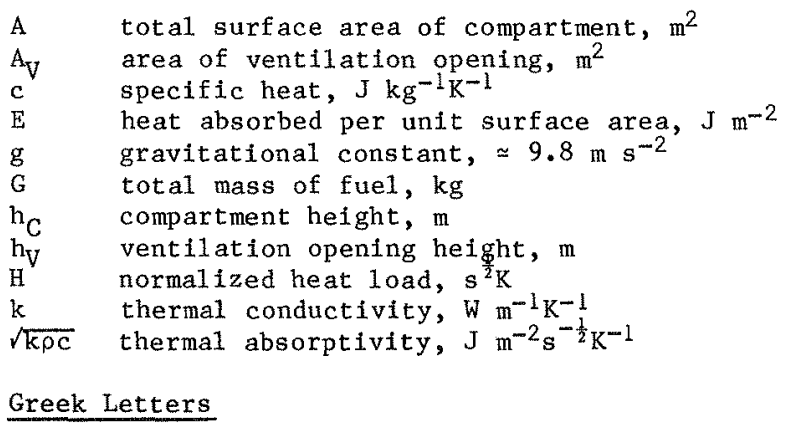

$\delta$ fractional heat release from fuel inside the compartment

$\rho$ density, $\mathrm{kg} \mathrm{m}^{-3}$

$P_{a}$ density of atmospheric air, $\mathrm{kg} \mathrm{m}^{-3}$

$\Phi^{\mathrm{a}} \quad$ ventilation factor, $\mathrm{kg} \mathrm{s} \mathrm{s}^{-1}$

$\varphi$ specific surface of the fuel, $\mathrm{m}^{-2} \mathrm{~kg}^{-1}$

\section{Subscript}

1 of or for the 1 -th compartment boundary 


\section{REFERENCES}

1. Harmathy, T.Z., and Mehaffey, J.R., "Post-flashover compartment fires," Fire and Materials, 7, 49 (1983).

2. Harmathy, T.Z., "The possibility of characterizing the severity of fires by a single parameter," Fire and Materials, 4, 71 (1980).

3. Harmathy, T.Z., "The fire resistance test and its relation to real-world fires," Fire and Materials, 5, 112 (1981).

4. Harmathy, T.Z., and Mehaffey, J.R., "Normalized heat load: A key parameter in fire safety design," Fire and Materials, 6, 27 (1982).

5. Harmathy, T.Z., "Fire Severity: Basis of fire safety design," in Fire Safety of Concrete Structures, American Concrete Institute, ACI Publication SP-80, p. 115 (1983).

6. Harmathy, T.Z., "A new look at compartment fires, Parts I and II, "Fire Technology, 8, 196 and 326 (1972).

7. Mehaffey, J. $\vec{R}_{0}$, and Harmathy, T.Z., "Assessment of fire resistance requirements," Fire Technology, 17, 221 (1981).

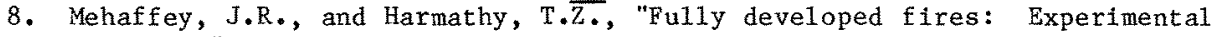
findings," Proceedings of the Third Symposium on Combustibility and Plastics, Society of the Plastics Industry of Canada, 24 and 25 Oct. 1983.

9. Pettersson, O., Magnusson, S.E., and Thor, J., "Fire engineering design of steel structures," Swedish Institute of Steel Construction, Stockholm, Bulletin 50 (1976).

10. Choi, K.K., "Effects of foamed plastic insulation on severity of room fires." To be published.

This paper is a contribution from the Division of Building Research, National Research Council of Canada. 